\title{
Preventing of flooding phenomena on vacuum distillation trays column via controlling coking value factor
}

\author{
Hossein Peiravan ${ }^{1}$. Ali Reza llkhani ${ }^{1} \cdot$ Mohammad Javad Sarraf $^{2}$
}

Received: 26 February 2020 / Accepted: 30 August 2020 / Published online: 11 September 2020

(c) Springer Nature Switzerland AG 2020

\begin{abstract}
The occurrence of flooding phenomena (FP) on the vacuum distillation trays column (VDTC) is investigated on a refinery in the middle region of Iran. Accumulation of coke sediment that is occasionally observed in refinery processing using coal $\operatorname{tar}(\mathrm{CT})$ feeding is the main reason of the FP on VDTC. This usually occurs at the down-comer areas and the seal pans of the column. Quinolone insoluble (QI) and toluene insoluble (TI) parameters, two routine methods used to measure coke containing sediments, are employed to determine probable critical areas of FP at the down-comers and the seal pans of CT feed in this study. Analyzing the obtained results of QI and TI tests demonstrated that FP at the column is directly related to the quality of CT feeding. For instance, when the QI of the inlet CT in battery 1 increases from $0.56 \% \mathrm{~W}$ in the first sample to $6.5 \% \mathrm{~W}$ in the 25 th sample, the vacuum pressure at the top of the distillation column is reduced from -230 mbar to -420 mbar. To prevent sediment accumulation of coke and the occurrence of FP, the CT feeds are centrifuged to reduce coke sedimentation at the down-comer areas and the seal pans of VDTC. Moreover, the seal pan trays are replaced by normal ones and all moveable valves with $25 \mathrm{~mm}$ diameter on trays 15 and higher in the column, where coke sediment accumulation is observed the most, are modified by installing wider fixed valve ( $40 \mathrm{~mm}$ diameter) trays.
\end{abstract}

\section{Graphic abstract}
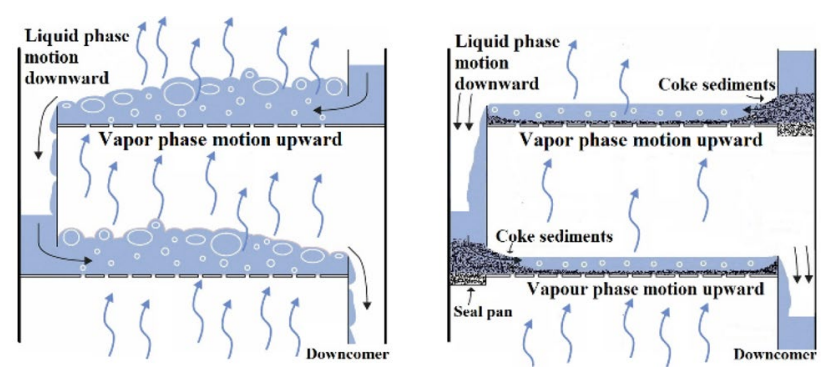

Keywords Flooding phenomena on distillation column - Coking value factor - Sediment accumulation of coke . Quinolone insoluble parameter · Toluene insoluble parameter

Ali Reza Ilkhani, ilkhaniali@iauyazd.ac.ir | ${ }^{1}$ Department of Chemistry, Yazd Branch, Islamic Azad University, Yazd, Iran. ${ }^{2}$ Department of Chemical and Polymer Engineering, Faculty of Engineering, Yazd University, Yazd, Iran. 


\section{Introduction}

Flooding phenomena (FP) is an abnormal problem in the separation of products in refineries [1-3]. The FP occurs inside the distillation column when the volume of the stream of vapors that travel up and liquids flow down do not equalize and the balance of mass transfer on trays is disrupted. Vapor/liquid contact is facilitated in the trays of the distillation trays column (DTC). In other words, the equilibrium between liquid evaporation and vapor condensation is balanced using the trays $[4,5]$. There is a simple rule that should be obeyed for the design of any distillation column; the stream vapors traveling upward and the liquids leaving downward from each tray of the column, must be equal. Any reasons that cause high liquid loads in trays will increase the risk of FP and negatively affect the performance and maximum capacity of the column. Indeed, during FP on the DTC, liquids are heavily accumulated in trays and prevent the vapors from traveling upward in the column [1-3]. FP is generally caused by spray entrainment flooding and froth entrainment flooding mechanisms. Those mechanisms may occur through down-comers malfunctioning and design defects in large diameter columns [1]. The occurrence of FP on the vacuum distillation trays column (VDTC) is also revealed by increased pressure inside the column which significantly decreases the purification efficiency of products [3]. A method for detecting flooding in a distillation column was invented by Pihlaja and Miller and the required devices were made to detect the differential pressure signal, filter the signal, and indicate the flooding generated in the distillation column [6].

The packed distillation column (PDC) is a common beneficial distillation setup that can be used instead of the tray distillation method to improve the separation yield of isotope components in a fluid mixture. The advantages of PDC in comparison with VDTC are that more vapor/liquid contact, as well as offering a lower pressure drop for a better separation in a distillation column. The essential difference between these separation methods is that the vapor/liquid contact in a PDC is continuous, rather than stepwise, as in a VDCT.

The computation and modeling of the fluid behavior inside PDCs have been reviewed by Amini and Nasr Esfahany [7]. The wire gauze structured packing, as an efficient system to evaluate the performance in distillation column, was carried out to study the mass transfer characterization in a PDC [8-10]. The influence of the application of nano-refrigerant particles was investigated on the mass fraction, flow rate, vapor quality parameters and boiling heat transfer coefficient within flattened pipes in a fabricated experimental system [11]. Additionally, application of nanoparticles with the goal of enhancing heat transfer in an energy storage unit was studied [12].

Coal $\operatorname{tar}(\mathrm{CT})$ is a black, high-viscosity liquid that is a byproduct of coke processing via natural coal $(2-8 \% \mathrm{~W}$ water content) heating processes in steel plants [13-16]. To coke the coal, natural coal is heated inside a special reactor, called a battery, at $1100-1200^{\circ} \mathrm{C}$ for $15 \mathrm{~h}$ under an Argonne atmosphere. The CT vapors $\left(300-350^{\circ} \mathrm{C}\right.$ ) are vacuumed by liquid ring pumps and condensed as a liquid product. The coking unit of the Esfahan steel plant factory is the source of the raw CT used for the VDTC of the refinery. There are several properties of crude $C T$ including density and water percentage, that should be considered for the use of CT as a raw material in industry as well as the distillation process. Those mentioned properties are characterized and monitored by the quality control lab of the steel plant at the beginning and before storage in supply tanks [17-19] of which, some significant properties and their acceptable ranges of the crude $\mathrm{CT}$ are reported in Table 1 and compared with the National Iranian Oil Company standards for the crude oil feed [20].

The composition of CT contributes heavily to the quality of the CT that is used in industry. Therefore, CT products may be classified into different grades based on their chemical contents and the density of the crude CT. Accordingly, four different grades of CT are produced by coking unit of the Esfahan steel plant factory that is used as inlet CT feeds of the refinery as listed in Table 2.
Table 1 Properties of crude coal tar as a product of the coking unit of the Esfahan steel plant factory in comparison with the National Iranian Oil Company standards for the crude oil feed using in the refinery and their acceptable ranges

\begin{tabular}{llll}
\hline Properties of crude coal tar feed & Characteristics & Properties of crude oil feed & Characteristics \\
\hline Uniformity & No separation & Uniformity & No separation \\
Density at $25^{\circ} \mathrm{C}$ & $1200-1600 \mathrm{~kg} \mathrm{~m}^{-3}$ & Density at $15^{\circ} \mathrm{C}$ & 856.8 \\
Residues by evaporation & $>47 \% \mathrm{~W}$ & Sulfur content & $1.46 \% \mathrm{~W}$ \\
Water content & $1-5 \% \mathrm{~W}$ & Water content & $<0.5 \% \mathrm{~V}$ \\
Residues weight loss & $<10 \% \mathrm{~W}$ & Wax content & $4.8 \% \mathrm{~W}$ \\
Solubility of residues in $\mathrm{CS}_{2}$ & $>20 \% \mathrm{~W}$ & Asphaltene content & $1.6 \% \mathrm{~W}$ \\
Ash content of residues & $30-40 \% \mathrm{~W}$ & Metal content & $<60 \mathrm{mg} \mathrm{Kg}^{-1}$ \\
Drying time film (firm set) & $<8 \mathrm{~h}$ & Vapor pressure & $895 \mathrm{psi}$ \\
\hline
\end{tabular}


Table 2 Classification of coal tar product of the Esfahan steel plant factory based on chemical contents (in \%W) and density (in $\mathrm{Kg}$ $\mathrm{m}^{-3}$ ) that as used inlet feeds in the refinery

\begin{tabular}{lllll}
\hline Properties & \multicolumn{4}{l}{ Coal tar classification } \\
\cline { 2 - 5 } & Grade-1 & Grade-2 & Grade-3 & Grade-4 \\
\hline Density $\left(\mathrm{Kg} \mathrm{m}^{-3}\right)$ & 1163 & 1203 & 1205 & 1231 \\
Water content $(\% \mathrm{~W})$ & 2.4 & 2.7 & 1.4 & 1.1 \\
Light oil (\%W) & 4.6 & 2.03 & 3.12 & 1.63 \\
Creosote oil (\%W) & 1.26 & 0.5 & 0.29 & 0.34 \\
Heavy oil (\%W) & 22.81 & 16.4 & 25.09 & 19.23 \\
Naphthalene (\%W) & 6 & Trace & 0.2 & 1.72 \\
Anthracene (\%W) & 0.6 & Trace & 0.19 & 0.24 \\
\hline
\end{tabular}

The water content and the density are two extremely important properties of the crude CT that must carefully controlled before any usage as an inlet feed of refinery. Acceptable ranges of those important parameters have been defined by the refinery designer company through the American Society for Testing and Materials (ASTM) and other standard methods. The mentioned acceptable ranges of density and water percentage of crude CT for the refinery are $1100-1250 \mathrm{~kg} \mathrm{~m}^{-3}$ and $1-3 \% \mathrm{~W}$, respectively.

Due to the risk of explosion, the excess water of outof range $\mathrm{CT}$ must be eliminated before distillation in the column. To reduce the water, crude CT is pumped to the dehydration unit which converts it to the suitable CT.
Another important property for crude CT is coke content. The presence of insoluble particles in crude $C T$ is the main reason for sediment accumulation on trays. The particles precipitate specifically on seal pan areas and the downcomers of the column.

Determining quinoline insoluble $(\mathrm{QI})$ and toluene insoluble ( $\mathrm{TI})$ parameters are two common experimental methods to control the capacity of insoluble particles in crude CT [13-15]. Moreover, the measurement of the coking value (CV) factor is a well-known test that is usually employed to determine the amount sedimentation of coke for crude CT [21-23].

For reducing the sedimentation of unreacted natural coke and values insoluble particles of $\mathrm{CT}$, out-of range crude $\mathrm{CT}$ liquid is transferred to a mechanical filtering process unit. Figure 1 reveals the flow transferring process from the CT vapor to the distillation column using a filtration centrifuge process [24-28].

Due to the thermal cracking of high molecular weight components that are present in CT [29-31], the distillation process is accomplished under vacuum below $300^{\circ} \mathrm{C}$. The advantages of vacuum distillation processing are increasing relative volatilities at lower pressures and reducing the temperature requirement at lower pressures in the system $[32,33]$.

The CT feeds to the VDTC from E position on tray number 15 at $110-120^{\circ} \mathrm{C}$ (Fig. 2). While, the $\mathrm{CT}$ temperature at the bottom of VDTC is designed for $231.7^{\circ} \mathrm{C}$ (T position),

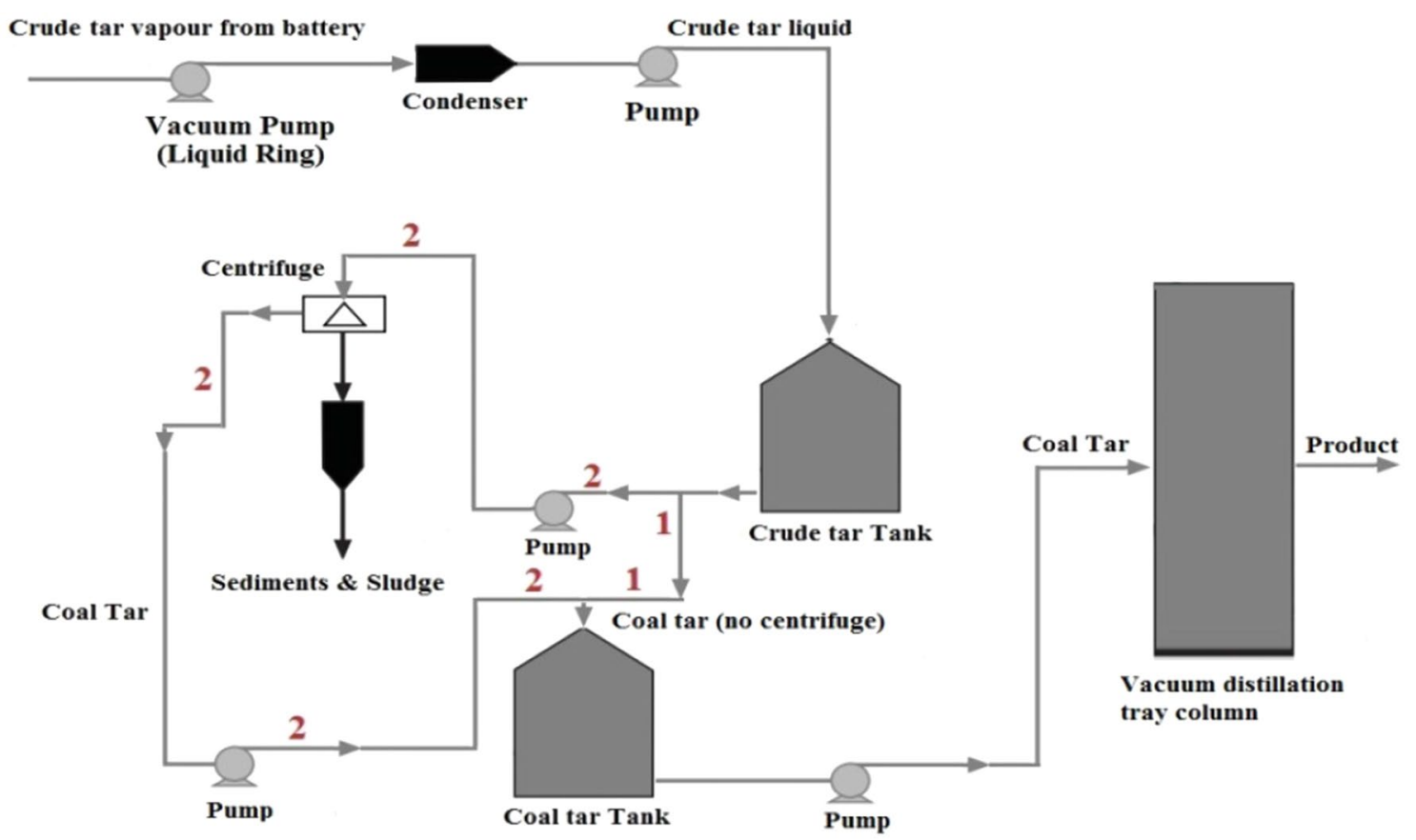

Fig. 1 Storing a coal tar liquid with an acceptable insoluble particles value (pathway 1 ) and an out-of range crude tar liquid after a centrifuging step (pathway 2) in a coal tar tank 


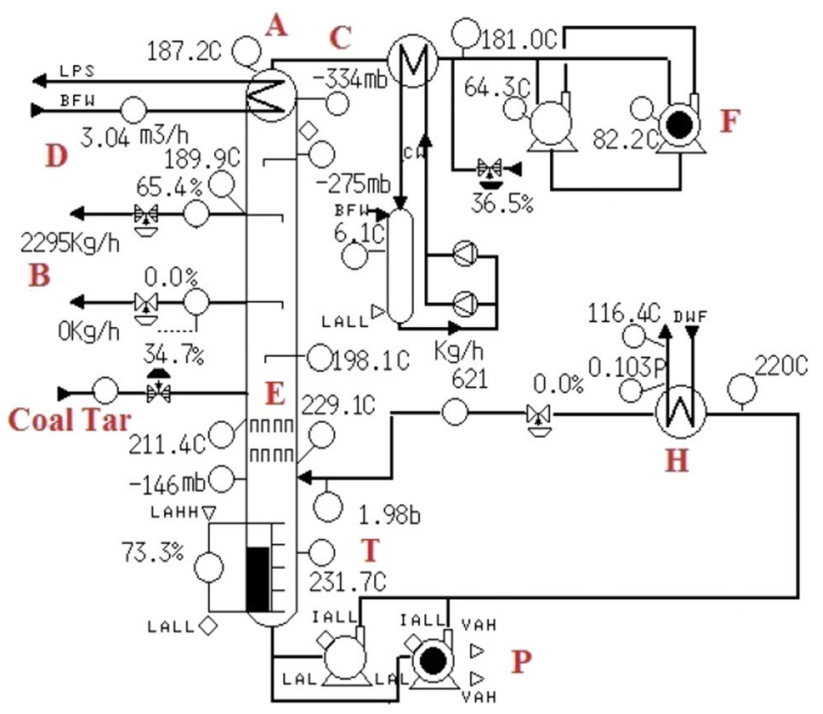

Fig. 2 Schematic of vacuum distillation tray column on a refinery in the middle region of Iran

$\mathrm{CT}$ has been pumped to $\mathrm{H}$ heat exchanger through $\mathrm{P}$ centrifuge pumps [34-36] to $\mathrm{H}$ heat exchanger and it heat up to $250^{\circ} \mathrm{C}$ [37-40]. The Shell \& Tube condenser A [41-44] condenses the $\mathrm{CT}$ vapors to $\mathrm{CT}$ liquid by injecting fresh water at $\mathrm{D}$ position. Critical pressure condition of column is designed for -390 up to -420 mbar. The vacuum pressure is controlled at $C$ position of the VDTC that provides by $F$ liquid ring pumps [45-48]. The output product of distillation exits from B position of the VDTC.

\section{Methods}

\subsection{Quinoline insolubility parameter}

Based on ASTM (D 2318-15) and ANSI/ASTM (D 47461998) standards, approximately $1.5 \mathrm{~g}$ of CT is poured into an Erlenmeyer flask and dissolved with $50 \mathrm{~mL}$ quinoline $[49,50]$. The collection is then placed in a Binder model oven Fig. $3 a$ at $80^{\circ} \mathrm{C}$ for 20 min. Following weighting CT and quinoline samples from the oven is poured onto filter paper (Watman number GF/C, $70 \mathrm{~mm}$ ) and connected to a round-bottom flask under vacuum (Fig. $3 b$ ). In principle, the vacuum conditions speed up the sedimentation of the sample on to the filter paper and will increase the filtration process efficiency. After filtering the sediment, they are oven heated at $110^{\circ} \mathrm{C}$ for $2 \mathrm{~h}$ and weighed when cooled.

\subsection{Toluene insolubility parameter}

Experimental testing of insolubility of toluene in $C T$, in accordance with ASTM (D 4072-98) and ANSI/ASTM (D 4072-98) R2004 standards, is likely to be insoluble in quinoline. At first $2 \mathrm{~g}$ of CT and $100 \mathrm{~mL}$ of toluene is poured in the Erlenmeyer flask and left in the oven for $30 \mathrm{~min}$ at $150^{\circ} \mathrm{C}[51,52]$. Also, the cooling time decreased from 2 to $1.5 \mathrm{~h}$. Equation (1) is used to determine the insolubility parameters of the $C T$ in quinoline and toluene.

Insolubility Parameters $=\frac{W_{2}-W_{1}}{W_{t}} \times 100$

$w_{1}, w_{2}$, and $w_{t}$ introduce initial weight of filter paper, filter paper and sediment weights, and the initial weight of CT in $\% \mathrm{~W}$, respectively.

\subsection{Coking value factor}

According to ISO (6998-97) standard, the amount of CT $(2 \mathrm{~g})$ is poured in crucible which is a weighted and placed in the preheated oven, then placed in a small nickel crucible. The sides of crucible are filled with coking particles to properly direct the heat off the furnace of crucible body and prevent thermal mutation error. Crucible with the small nickel crucible is placed in an electric heat furnace at $550^{\circ} \mathrm{C}$ for $2.5 \mathrm{~h}$ (see Fig. 3c). Then the small nickel crucible and crucible is removed from the electric furnace. After cooling, the crucible containing coke particles also a

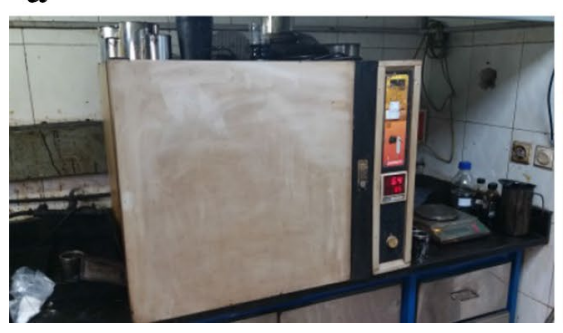

b

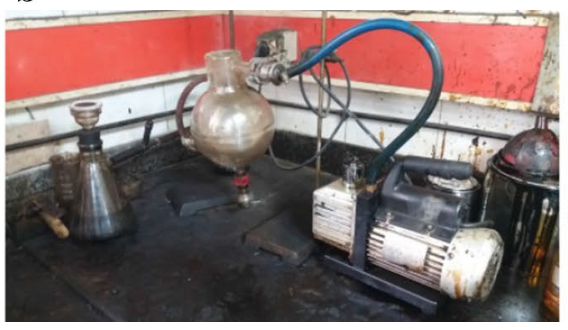

c

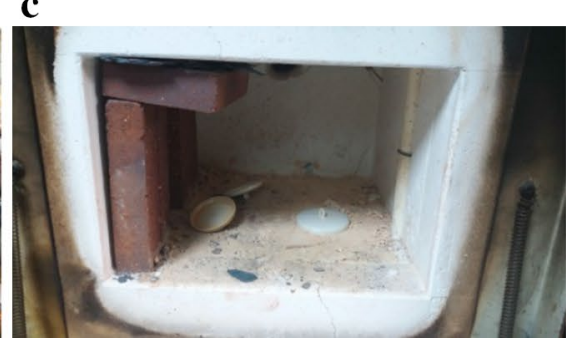

Fig. 3 Equipment used to measure the insolubility of CT in quinoline and toluene and coke value; oven modeling Binder (a), equipment of vacuum package included round-bottom flask and vacuum pump (b), electric heat furnace (c) 
weighed [53]. Equation (2) is used for determining of CV in CT.

Coking Value $=\frac{\mathrm{W}_{2}-\mathrm{W}_{1}}{\mathrm{~W}_{\mathrm{t}}} \times 100$

In the equation above $w_{2}$ is the weight of crucible and the coking particles involved, $w_{1}$, is the initial weight of crucible where $w_{t}$ is the initial weight of CT (\%W). The approved ranges and related standard measurement methods for $\mathrm{QI}$ and $\mathrm{TI}$ parameters and CV factor are presented in Table 3.

Figure 3 shows the laboratory equipment used in this study to measure the insolubility of $\mathrm{CT}$ in quinoline and toluene and $\mathrm{CV}$ :

\section{Results and discussion}

\subsection{Analysis on data of coal tar quality determination}

Data from recorded values for QI, TI parameters in CT and CV factor of before and after centrifuging [22-28] are collected in period of receiving coal feed inlet to distillation column in the years 2017-2018 was gathered (Table 2). These results are for two different feed samples of differing quality classified as received from batteries 1 and 3 of the steel plant. In general, the feed quality received from battery 1 was always higher than that of battery 3 of steel plant. The difference in feed quality depends on to the heating conditions of coal and the condensation of vapors of CT [17-19]. The type of coal used in the steel plant was constant during this period.

In order to analysis the effects of using centrifuges for the feeding of CT on the VDTC, the recorded data in Table 4 are plotted in Fig. 4. The variation of $\mathrm{QI}, \mathrm{TI}$, and CV parameters belonging to each sampling number, before applying a centrifuge step on the feed to the distillation column, shown in diagrams (a), (b), and (c) of the figure, respectively.

It can be seen from Fig. 4 and Table 2 in diagrams (a, $b$, and c) from samples 1 to 7, the parameters of QI, TI, and $\mathrm{CV}$ for CT feed have been placed in suitable bounds which indicates the received CT quality from the steel plant is

Table 3 Approved ranges for quinoline insoluble and toluene insoluble parameters and coking value factor

\begin{tabular}{llll}
\hline & $\begin{array}{l}\text { Quinoline } \\
\text { insoluble (QI) }\end{array}$ & $\begin{array}{l}\text { Toluene insolu- } \\
\text { ble (TI) }\end{array}$ & $\begin{array}{l}\text { Coking value } \\
(\mathrm{CV})\end{array}$ \\
\hline $\begin{array}{l}\text { Approved range } \\
(\% \mathrm{~W})\end{array}$ & $1-10$ & $3-15$ & $18-25$ \\
\hline
\end{tabular}

proper. Thus, it is obvious that the received CT feed of battery 3 lower quality than battery 1 . In sample number 8 , a significant increase in weight percent of quinoline and toluene insolubility parameters and CV were observed. In particular, the slope of the increasing trend was more noticeable for the insolubility parameters of quinoline and toluene. This increase in weight percent (\%W) in insoluble sediments is more significant for the insolubility index of toluene than quinoline. Lower quality of CT feed inlet to distillation column from battery 3 of steel plant, due to sudden jump of these indices between sample 7 and 8. The upward trend of these indices in samples 8 to 15 continues, with samples above 30 likely to have the distillation column near critical conditions. Thus, the distillation column was shut down in sample 25 and put out of service (overhaul). During the six-month overhaul period, the distillation column of 25 samples of CT feed to the refinery were carried out in depot storage tanks. During this period, CT storage tanks were sampled at 4-day intervals. The samples were centrifuged at a speed of $2000 \mathrm{rpm}$, equivalent to the operating conditions of the centrifuge used in the refinery [24-28] After performing a centrifugation step in the laboratory, the insoluble parameters of quinoline and toluene solvents and the coke content in the depot $\mathrm{CT}$ feed from batteries 1 and 3 were determined, the results of which are shown in Fig. 5.

Consequently, after centrifuging at $2000 \mathrm{rpm}$ on the CT feed to the distillation column, it was observed that the insolubility parameters of quinoline solvent and toluene solvent in $\mathrm{CT}$ and the amount of $\mathrm{CV}$, in diagrams $(a, b$, and c) of samples 26 to 38 , had a noticeable decreasing trend and are in the permissible range again.

\subsection{Select the suitable tray in vacuum distilled column}

During the overhaul process, intense accumulation of coke containing sediments was observed in the distillation column. However, the bulk of these sediments accumulated on trays number 11 and above, especially in the downcomer and seal pan areas of the trays [4,5]. The accumulation of coke containing sediments on tray 22 indicated the intensity of coke deposition in the movable valves of the seal pan tray, which is illustrated in Fig. 6a, b.

Due to the over accumulation of coke containing sediments in the tray valves, Fig. 6a, b seal pan areas observed during the overhauling of the distillation column, changes to the tray designs were decided upon. For this purpose, to minimize sediment accumulation, the first removable tray valves with fixed valves, having the highest resistance to deposition, were replaced. In addition, the diameter of the valves also increased from $25 \mathrm{~mm}$ to $40 \mathrm{~mm}$ to minimize the accumulation of sediments, this also facilitates 
Table 4 Recorded data for the insolubility of quinoline solvent, toluene solvent in coal tar for batteries 1 and 3 and coke value factor within 2 year

\begin{tabular}{|c|c|c|c|c|c|c|c|c|c|c|c|c|c|c|c|}
\hline \multicolumn{4}{|c|}{ Battery 1} & \multicolumn{4}{|l|}{ Battery 1} & \multicolumn{4}{|c|}{ Battery 3} & \multicolumn{4}{|l|}{ Battery 3} \\
\hline Sample & QI \%W & TI \%W & CV \%W & Sample & QI \%W & TI \%W & CV \%W & Sample & QI \%W & TI \%W & CV \%W & Sample & QI \%W & TI \%W & $\mathrm{CV} \% \mathrm{~W}$ \\
\hline 1 & 0.56 & 1.5 & 19.3 & 20 & 4.5 & 8.5 & 29.2 & 1 & 1.2 & 4 & 23 & 20 & 15 & 19.54 & 32.5 \\
\hline 2 & 0.86 & 1.4 & 19.5 & 21 & 5 & 8.43 & 28.7 & 2 & 1.6 & 4.6 & 22.3 & 21 & 14.95 & 19.2 & 33.6 \\
\hline 3 & 0.6 & 1.49 & 19 & 22 & 5.3 & 9.23 & 29 & 3 & 1.5 & 4.95 & 20.5 & 22 & 14.6 & 20.1 & 32.9 \\
\hline 4 & 0.6 & 1.6 & 19.6 & 23 & 5.7 & 9.5 & 29.3 & 4 & 1.65 & 4.31 & 21.42 & 23 & 15.1 & 23 & 33.7 \\
\hline 5 & 0.6 & 1.9 & 20 & 24 & 6 & 10.3 & 29.8 & 5 & 1.55 & 4 & 22.2 & 24 & 14.35 & 23.1 & 33.5 \\
\hline 6 & 0.55 & 2.1 & 20.6 & 25 & 6.2 & 9.8 & 28.1 & 6 & 1.36 & 4.6 & 23.1 & 25 & 14.95 & 24.5 & 35.6 \\
\hline 7 & 0.43 & 1.85 & 21.3 & 26 & 6.5 & 8.7 & 28 & 7 & 1.5 & 5 & 21.8 & 26 & 14.56 & 26.2 & 36.9 \\
\hline 8 & 0.8 & 1.69 & 21.9 & 27 & 4 & 6.5 & 22 & 8 & 2 & 4.46 & 22.5 & 27 & 13.31 & 25.6 & 37 \\
\hline 9 & 0.9 & 2.6 & 22 & 28 & 3.8 & 7.2 & 19.7 & 9 & 2.5 & 12.5 & 23.6 & 28 & 13.65 & 18.65 & 25 \\
\hline 10 & 1.8 & 4.5 & 23.3 & 29 & 3.2 & 6.32 & 19.5 & 10 & 4.5 & 15.23 & 27.6 & 29 & 12.95 & 15.33 & 24 \\
\hline 11 & 2.7 & 5.9 & 23.5 & 30 & 3.1 & 6 & 19 & 11 & 6.42 & 16.2 & 27.1 & 30 & 11.22 & 14.26 & 23 \\
\hline 12 & 2.9 & 6.2 & 22.9 & 31 & 3 & 5.82 & 17 & 12 & 8.6 & 15.99 & 26.9 & 31 & 10.1 & 12 & 22 \\
\hline 13 & 3.2 & 6.1 & 23 & 32 & 2.5 & 5.6 & 17.2 & 13 & 9.6 & 16.23 & 27.5 & 32 & 8.36 & 11.54 & 21.5 \\
\hline 14 & 3.1 & 6.44 & 26.9 & 33 & 2.6 & 4.26 & 16.9 & 14 & 13.33 & 15.93 & 28.1 & 33 & 7.1 & 10.8 & 21 \\
\hline 15 & 3.5 & 7.35 & 28.3 & 34 & 2.1 & 4.54 & 16.8 & 15 & 14.5 & 16.35 & 28.1 & 34 & 7 & 6.5 & 21.2 \\
\hline 16 & 4.5 & 8.45 & 27.5 & 35 & 1.4 & 3.5 & 16 & 16 & 14.53 & 18 & 29 & 35 & 6.36 & 5.2 & 21 \\
\hline 17 & 4.1 & 8.51 & 28.9 & 36 & 1.1 & 2.3 & 15.4 & 17 & 15.22 & 17.95 & 28.7 & 36 & 5.23 & 5.1 & 21.5 \\
\hline 18 & 4.8 & 8.1 & 28.8 & 37 & 0.9 & 2.1 & 15 & 18 & 14.9 & 17.6 & 29.3 & 37 & 2.3 & 4.8 & 20 \\
\hline 19 & 4.6 & 8.36 & 29 & 38 & 0.85 & 2 & 15.1 & 19 & 15.21 & 18.56 & 30.1 & 38 & 2.1 & 4.8 & 20.5 \\
\hline
\end{tabular}
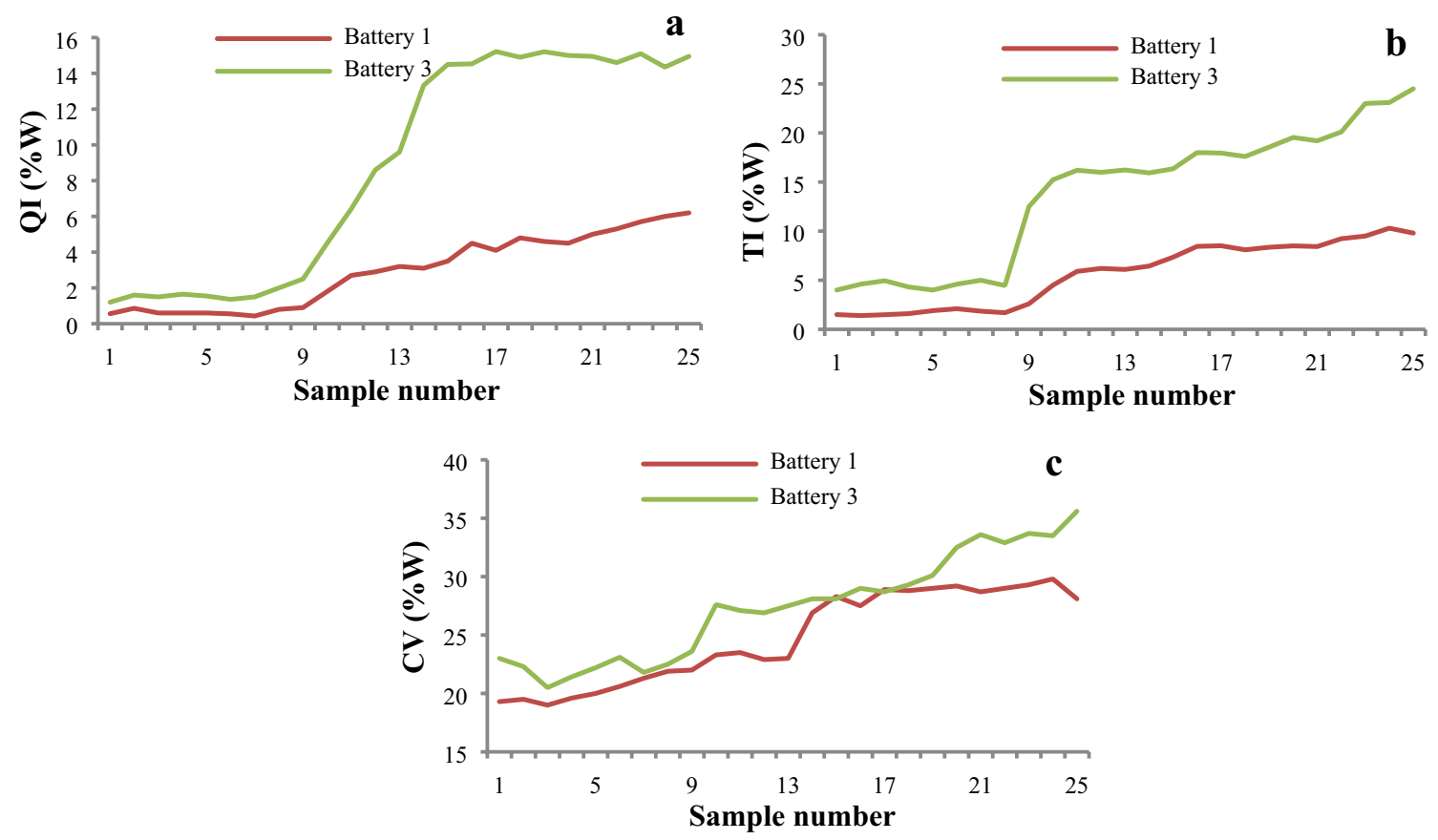

Fig. 4 The parameters of quinoline insoluble (a), toluene insoluble (b) and coking value (c) in entrance coal tar feed to distillation column for batteries 1 and 3 in 20 days 

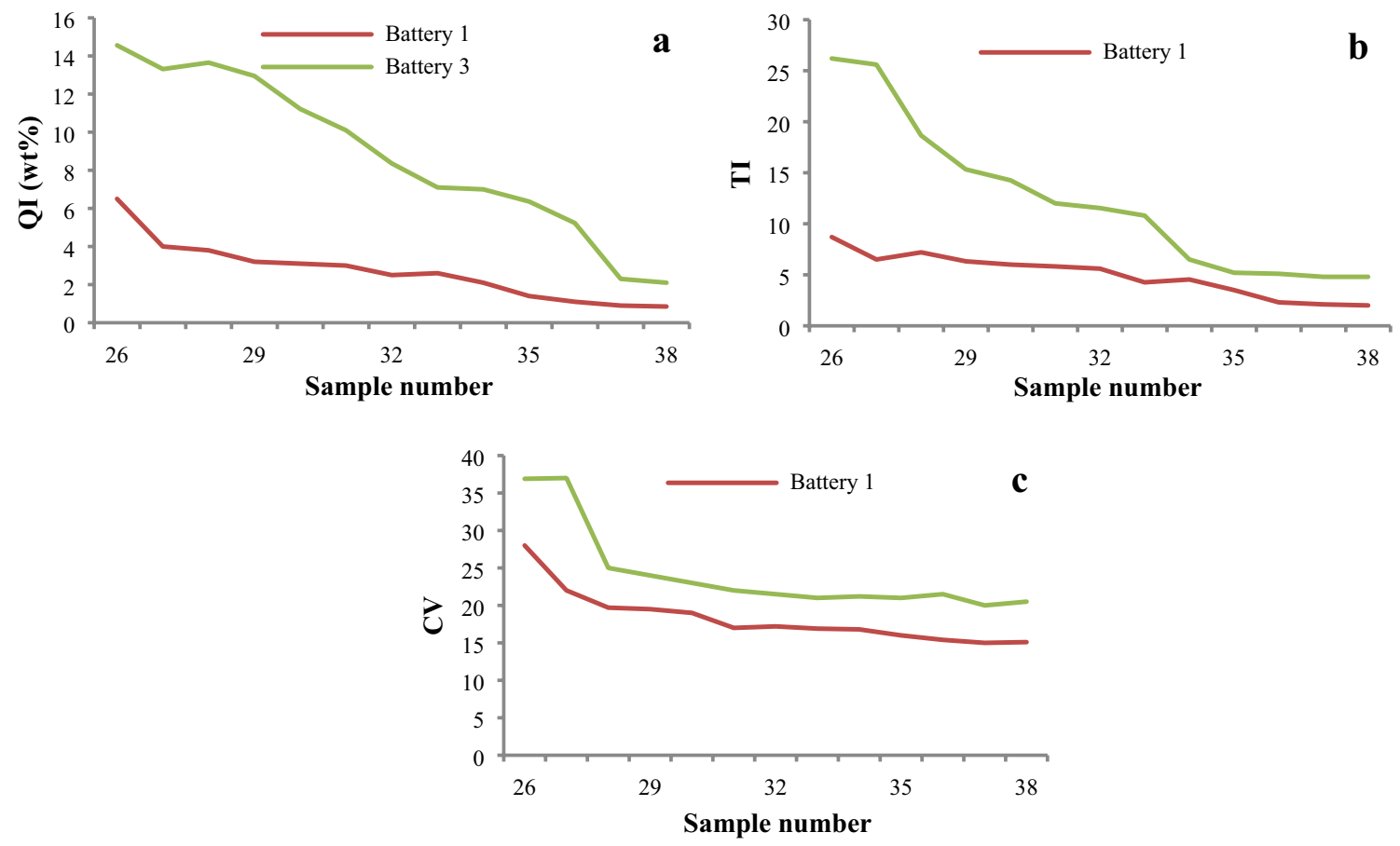

Fig. 5 Parameters of quinoline insoluble (a), toluene insoluble (b) and coking value (c) measured in depot coal tar feed from batteries 1 and 3 after applying a centrifuge step in the laboratory for 4-days

a

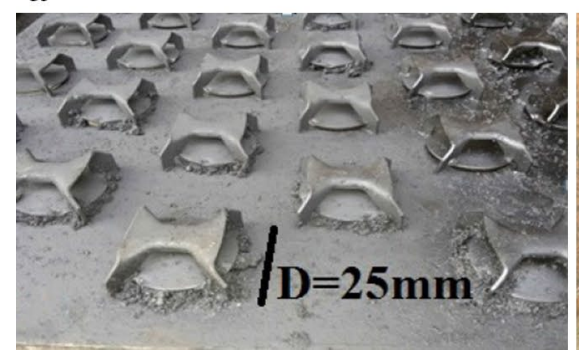

b

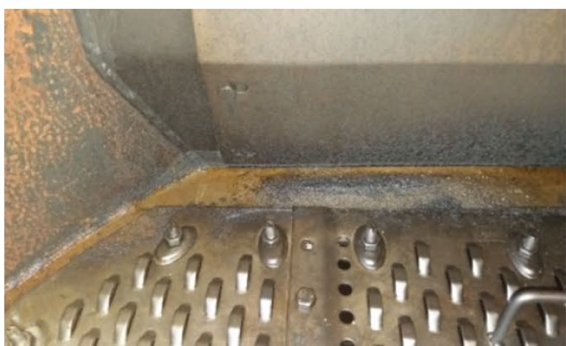

c

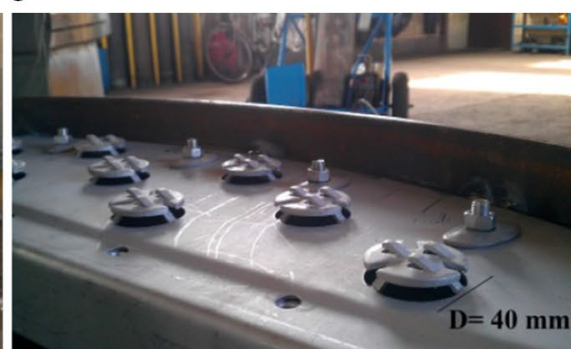

Fig. 6 Tray number 22 vacuum distillation column with $30 \mathrm{~mm}$ depth and $25 \mathrm{~mm}$ diameter movable valves (a, b), new design on tray number 22 by removing seal pan and inserting $40 \mathrm{~mm}$ diameter fixed valves (c)

passage of the vapor phase through the liquid phase (Fig. 6c). Observations made during the overhaul revealed that one of the main factors for sediment accumulation on distillation trays, the input feed CT is capability for forming sediments is the seal pan in the down-comer area. In fact, the $30 \mathrm{~mm}$ depth of the seal pans Fig. $6 \mathrm{~b}$ was a suitable place for sediment accumulation. Figure 7 a shows the difference between a seal pan tray and tray without seal pan Fig. $7 \mathrm{~b}$ in the formation and accumulation of coke containing sediments.

In the new design, the trays used to minimize the accumulation of coke containing sediment were removed from the seal pan tray. In case of accumulation of sediments on the tray, the flow of liquid downstream would wash the sediments away. This way the duration of overhaul will be greatly reduced. After 6 months of working with the distillation column with the corrections made, the vacuum pressure top of the distillation column was again in the range of -390 to -420 mbar. Meanwhile, the vacuum pressure top of the distillation column was reduced to -230 mbar prior to the before making the above-mentioned corrections.

After completing the overhaul operation on the vacuum tray distillation column and replacing trays without seal pan instead of seal pan trays while also increasing tray diameter from 25 to $40 \mathrm{~mm}$, it was decided to be in service three months later. Taking the distillation column data on vacuum pressure recorded above the tower and 
Fig. 7 Demonstrate the movement of the liquid phase downward and the vapor upward in the distillation column and how coke containing sediments accumulate on the seal pan trays (a) and no accumulation of sediment on the trays without seal pan (b)

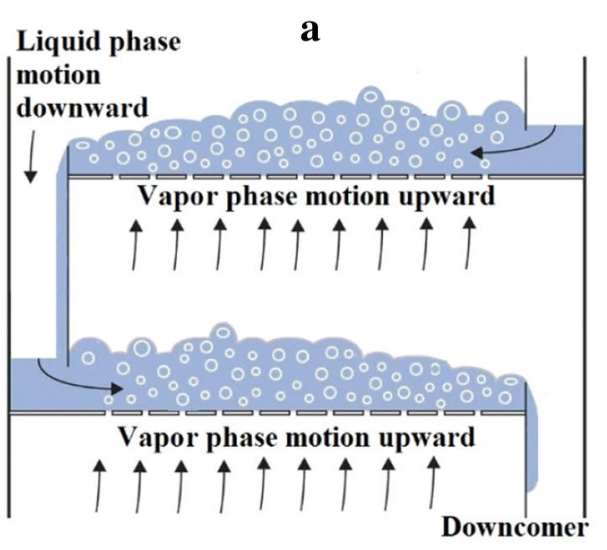

comparing them with the values recorded before the overhaul operation. The decision was made 3 months after the distillation column was put into service, vacuum pressure data from the top of the column is recorded and compared with those recorded before the overhaul operation. For this purpose, using the data recorded in Table 3: Fig. 8a for vacuum pressures recorded after correction and centrifuging process on the $\mathrm{CT}$ feed inlet to the distillation column and Fig. $8 \mathrm{~b}$ for vacuum pressures recorded before overhaul operation was drawn. The comparison between the two graphs shows how vacuum pressure drops at the top of the distillation column range from -400 to -230 mbar due to the heavy accumulation of coke containing sediments on the trays Fig. $8 \mathrm{~b}$. and then how to improve vacuum pressure from -240 to operating range $-410 \mathrm{mbar}$ shows due to the necessary modifications 3 months after

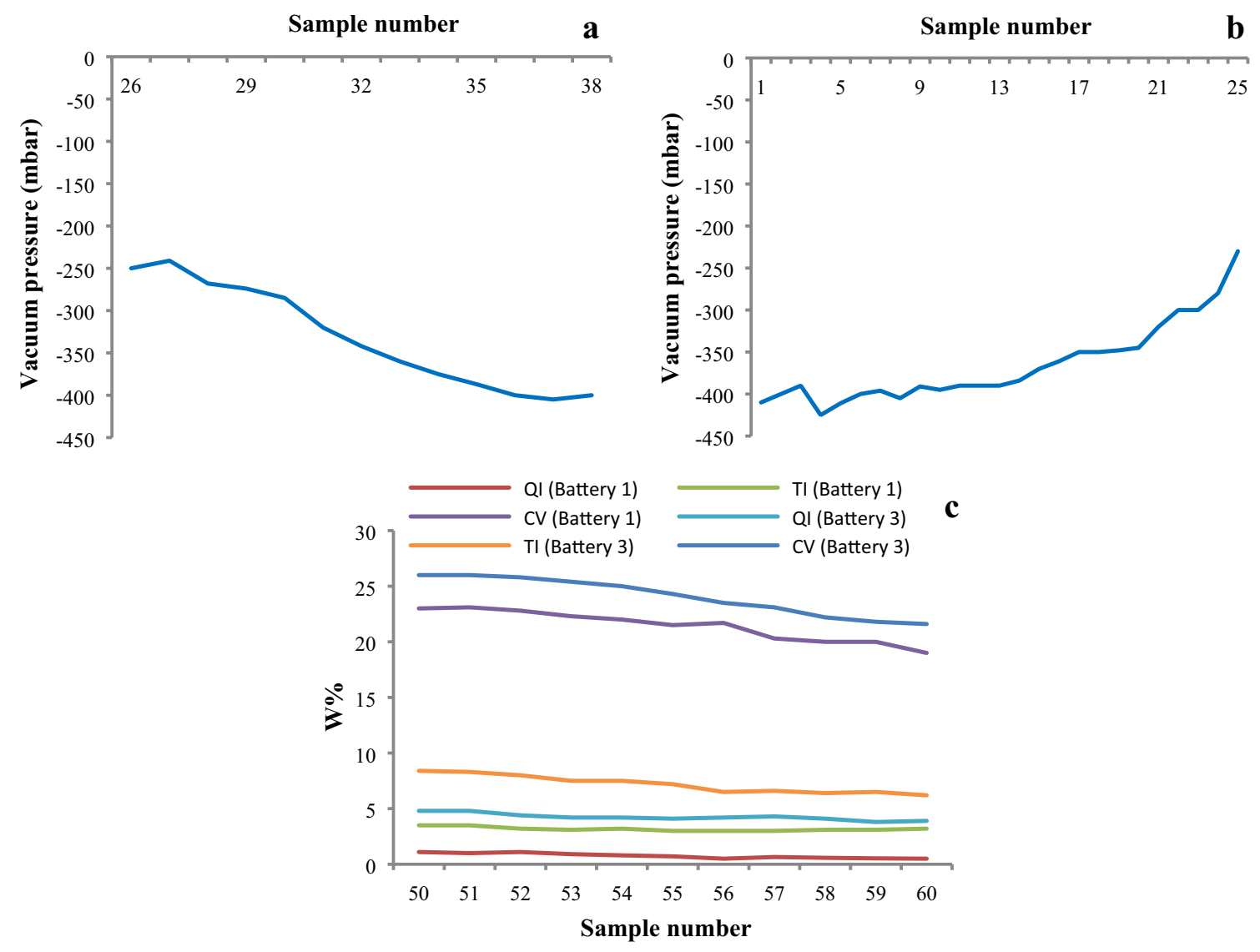

Fig. 8 Improvement the vacuum pressure of the distillation column during the 4 months before and 3 months after the overhaul and the centrifuge process on coal tar feed $(\mathbf{a}, \mathbf{b})$. Reduction of TI,
QI and CV parameters after centrifugation on feed coal tar inlet to distillation column over 9-day intervals (c) 
the distillation column was put into service, which resulted in a significant decrease in sediment accumulation Fig. 8 a.

On the other hand, in the 10 cases sampled (50 to 60) during the 3 months after the overhaul operation, as well as one centrifugation step on CT feed to distillation column, the method to reduce the insolubility parameters of quinoline and toluene solvents in $\mathrm{CT}$ and the $\mathrm{CV}$ was continued and reported for both battery 1 and battery 3 in Fig. 8c. From the results visible in the figure we can see that 3 months after overhaul, the weight percent of $\mathrm{QI}$, and TI parameters in the distillation column for both batteries are almost constant and are within the permissible range provided in Table 3 . In addition, the CV is slightly reduced which indicates that the centrifuge process is successful in improving CT feed quality as the input to the VDTC.

Although the CT centrifuge process is an excellent method to reduce of the coke sedimentation in the VCDT, it is a costly method and needs to add many expensive industrial facilities beside the distillation systems. Thus, the main strategy of this research is in the control of the QI, TI parameters and the $\mathrm{CV}$ to avoid centrifuging all the crude coal tar feeds before submitting it to the VCDT.

\section{Conclusion}

The flooding phenomena in the vacuum distillation trays column under study was due to the accumulation of coke containing sediments particularly in the areas of movable valves and seal pans tray number 11 or higher, as examined at the refinery. The feed quality of coal tar inlet to this distillation column was evaluated by the insolubility parameters of the quinoline solvent, the toluene solvent, and the coking value. For a one-year period, the results of the quinoline and the toluene insolubility experiments were increased respectively by 10 and 6 times while the coking value was raised $50-60 \%$. This indicates the necessity of using a centrifuge before the feed coal tar inlet to the distillation column. Consequently, the vacuum pressure top of the distillation column was reduced from -230 to the range of -390 to -420 mbar that could be taken as a clear sign of the flooding phenomena in the tower. In order to reduce the accumulation of coke sediment on the trays, modifications were made to the design of the tower: replacement of the $25 \mathrm{~mm}$ removable valves with the wider fixed valves ( $40 \mathrm{~mm}$ diameter) and removing the seal pans from the trays in the distillation column. After these modifications, passage of the vapor phase through the liquid phase is facilitated and the coke sediments on trays and down-comer areas of the column were simply flashed down. Thus, sudden increments of vacuum pressure were no longer observed during the 3 months of service of the vacuum distillation trays column. Moreover, the weight percent of quinoline and toluene insolubility parameters and coking value in coal tar do not climb as experienced before the centrifuging process and the distillation column manipulation. Due to the non-continuity of similarity of the inlet crude coal tar feed, the quinolone and toluene insolubility parameters and cocking value measurements were suggested as effective experimental methods to mitigate the effect of this non-similarity and reduced the risk of the flooding phenomena on vacuum distillation trays column. Pilot processing is useful to adjust the laboratory obtained results and their relations with semi-industrial attempts and is recommended for future directions for the research.

\section{Compliance with ethical standards}

Conflict of interest The authors declare that they have no conflict of interest.

\section{References}

1. Kister HZ (1990) Distillation operation, Chap 2. McGraw-Hill, New York

2. Kister HZ (2014) Common techniques for distillation troubleshooting. Distillation operation and applications distillation: Operation and applications, 37-110

3. Gu W, Huang Y, Wang K, Zhang B, Chen Q, Hui CW (2014) Comparative analysis and evaluation of three crude oil vacuum distillation processes for process selection. Energy 76:559-571

4. Brahem R, Royon-Lebeaud A, Legendre D, Moreaud M, Duval L (2013) Experimental hydrodynamic study of valve trays. Chem Eng Sci 100:23-32

5. Li X, Yan P, Zhao S, Li H, Gao X (2019) Fabrication and hydrodynamics performance of modified sieve tray with Janus feature. Sep Purif Technol 216:74-89

6. Pihlaja RK, Miller JP (2009) Detection of distillation column flooding US8216429B2

7. Amini Y, Nasr Esfahany M (2018) CFD simulation of the structured packings: a review. Sep Sci Technol 54:2536-2554

8. Amini Y, Karimi-Sabet J, Nasr Esfahany M, Haghshenasfard M, Dastbaz A (2018) Experimental and numerical study of mass transfer efficiency in new wire gauze with high capacity structured packing. Sep Sci Technol 54:2706-2717

9. Amini Y, Karimi-Sabet J, Nasr Esfahany M (2017) Experimental characterization of new wire gauze with high capacity structured packing. Can J Chem Eng 95:535-542

10. Amini Y, Karimi-Sabet J, Nasr Esfahany M (2016) Experimental characterization of new wire gauze high capacity structured packing with varied inclination angle. Chem Eng Technol 40:581-587

11. Sheikholeslami M, Rezaeianjouybari B, Darzi M, Shafee A, Li Z, Nguyen TK (2019) Application of nano-refrigerant for boiling heat transfer enhancement employing an experimental study. Int J Heat Mass Transf 141:974-980

12. Sheikholeslami M, Jafaryar M, Shafee A, Babazadeh H (2020) Acceleration of discharge process of clean energy storage unit with insertion of porous foam considering nanoparticle enhanced paraffin. J Clean Prod. https://doi.org/10.1016/j.jclep ro.2020.121206 
13. Wang $Y$, Jiang $G$, Zhang $S$, Zhang H, Lin X, Huang X, Fan M (2016) The application of a modified dissolving model to the separation of major components in low-temperature coal tar. Fuel Proc Technol 149:313-319

14. Shoko L, Beukes JP, Strydom CA, Larsen B, Lindstad L (2015) Predicting the toluene- and quinoline insoluble contents of coal tar pitches used as binders in Söderberg electrodes. Int J Miner Proc 144:46-49

15. Egashira R, Saito J (2007) Solvent extraction of coal tar absorption oil with continuous countercurrent spray column. J Jpn Petrol Inst 50:218-226

16. Egashira R, Salim C (2006) Separation of coal tar distillate by solvent extraction- separation of extract phase using distillation. J Jpn Petrol Inst 49:326-334

17. Mondal M, Mukherjee R, Sinha A, Sarkar S, De S (2019) Removal of cyanide from steel plant effluent using coke breeze, a waste product of steel industry. J Water Proc Eng 28:135-143

18. Zhang Y, Wei C, Yan B (2019) Emission characteristics and associated health risk assessment of volatile organic compounds from a typical coking wastewater treatment plant. Sci Total Environ 693:133417

19. Kozielska B, Konieczynski J (2015) Polycyclic aromatic hydrocarbons in particulate matter emitted from coke oven battery. Fuel 144:327-334

20. Crude oil, petroleum products and petrochemical trading guidebook (2013) Crude oil specifications. https://www.noic-intl.com/ EN/CrudeSpec.aspx. Accessed Sept 2013

21. Reddy BR, Shravani B, Das B, Dash PS, Vinu R (2019) Microwaveassisted and analytical pyrolysis of coking and non-coking coals: comparison of tar and char compositions. J Anal Appl Pyrol 142:104614

22. Liu Y, Yan H, Chen X, Feng X, Yang C (2019) Effect of blending ratio on coke morphology and composition in co-coking of vacuum residue and bio-tar. J Anal Appl Pyrol 142:104629

23. Huang $X$, Kocaefe D, Kocaefe Y, Bhattacharyay D (2016) Wettability of bio-coke by coal tar pitch for its use in carbon anodes. Colloids Surf A Physicochem Eng Aspects 490:133-144

24. Leung WWF (2016) Inferring in situ floc size, predicting solids recovery, and scaling-up using the Leung number in separating flocculated suspension in decanter centrifuges. Sep Purif Technol 171:69-79

25. Bell GRA, Symons DD, Pearse JR (2014) Mathematical model for solids transport power in a decanter centrifuge. Chem Eng Sci 107:114-122

26. Gleiss M, Hammerich S, Kespe M, Nirschl H (2017) Application of the dynamic flow sheet simulation concept to the solid-liquid separation: separation of stabilized slurries in continuous centrifuges. Chem Eng Sci 163:167-178

27. Lindner J, Nirschl H (2014) A hybrid method for combining HighGradient Magnetic Separation and centrifugation for a continuous process. Sep Purif Technol 131:27-34

28. Zhu GR, Tan W, Yu Y, Liu LY (2013) Experimental and numerical study of the solid concentration distribution in a horizontal screw decanter centrifuge. Ind Eng Res 52:17249-17256

29. Kaminski T, Husein MM (2018) Thermal cracking of atmospheric residue versus vacuum residue. Fuel Process Technol 181:331-339

30. Menshhein G, Costa V, Chiarello LM, Scharf DR, Simionato EL, Botton V, Meier HF, Wiggers VR, Ender L (2019) Experimental data of the distillation of bio-oil from thermal cracking of methyl ester in castor oil. Data Brief 25:104325

31. Thahir R, Altway A, Juliastuti SR, Susianto A (2019) Production of liquid fuel from plastic waste using integrated pyrolysis method with refinery distillation bubble cap plate column. Energy Rep 5:70-77
32. Wu Z, Xie L, Li Y, Wang Y, Wang X, Wan N, Huang X, Zhang X, Yang $M$ (2019) A novel application of the vacuum distillation technology in extracting origanum vulgare L. essential oils. Ind Crops Prod 139:111516

33. Odusote YA, Jabar JM, Bolarinwa HS, Akinbisehin AB (2019) Application of molecular interaction volume model in separation of Ti-Al alloys in vacuum distillation. Vacuum 169:108885

34. Deng H, Liu Y, Li P, Zhang S (2017) Whole flow field performance prediction by impeller parameters of centrifugal pumps using support vector regression. Adv Eng Softw 114:258-267

35. Wang J, Zhang L, Zheng Y, Wang K (2019) Adaptive prognosis of centrifugal pump under variab operating conditions. Mech Syst Signal Proc 131:576-591

36. Guo X, Zhu Z, Shi G, Huang Y (2017) Effects of rotational speeds on the performance of a centrifugal pump with a variable-pitch inducer. J Hydrodyn 29:854-862

37. Kücük H, Ünverdi M, Yılmaz MS (2019) Experimental investigation of shell side heat transfer and pressure drop in a minichannel shell and tube heat exchanger. Int J Heat Mass Transf 143:118493

38. Chen J, Lu X, Wang Q, Zeng M (2019) Experimental investigation on thermal-hydraulic performance of a novel shell-and-tube heat exchanger with unilateral ladder type helical baffles. Appl Therm Eng 161:114099

39. Kalapala L, Devanuri JK (2019) Parametric investigation to assess the melt fraction and melting time for latent heat storage material based vertical shell and tube heat exchanger. Sol Energy 193:360-371

40. Said Z, Rahman SMA, El Haj Assad M, Alami AH (2019) Heat transfer enhancement and life cycle analysis of a Shell-and-Tube heat exchanger using stable CuO/water nanofluid. Sustain Energy Technol 31:306-317

41. Pattanayaka L, Padhib BN, Kodamasinghc B (2019) Thermal performance assessment of steam surface condenser. Case Studies Therm Eng 14:100484

42. Haseli Y, Dincer I, Naterer GF (2008) Optimum temperatures in a shell and tube condenser with respect to exergy. Int J Heat Mass Transf 51:2462-2470

43. Singh SK, Sarkar J (2018) Energy, exergy and economic assessments of shell and tube condenser using hybrid nanofluid as coolant. Int Commun Heat Mass Transf 98:41-48

44. Kasumu AS, Nassar NN, Mehrotra AK (2017) A heat-transfer laboratory experiment with shell-and-tube condenser. Educ Chem Eng 19:38-47

45. Huang S, He J, Wang X, Qiu G (2017) Theoretical model for the performance of liquid ring pump based on the actual operating cycle. Int J Rotating Mach 3617321

46. Karlsen-Davies ND, Aggidis GA (2016) Regenerative liquid ring pumps review and advances on design and performance. Appl Energy 164:815-825

47. Zhang R, Guo G (2020) Experimental study on gas-liquid transient flow in liquid-ring vacuum pump and its hydraulic excitation. Vacuum 171:109025

48. Giegerich T, Day C (2013) Conceptuation of a continuously working vacuum pump train for fusion power plants. Fusion Eng Design 88:2206-2209

49. American Society for Testing and Materials, Standard test method for quinoline insoluble (QI) content of tar and pitch, ASTM (D 231ss8-1998), ASTM international, 1998, West Conshohocken, PA, USA

50. American Society for Testing and Materials, Test method for determination of quinoline insoluble (QI) in tar and pitch by pressure filtration, ANSI/ASTM D 4746-1998 (R2004), (Reaffirmation of ANSI/ASTM D 4746-1998): 1/20/2004, ASTM international, 2004, West Conshohocken, PA, USA 
51. American Society for Testing and Materials, Standard test method for toluene insoluble (TI) content of tar and pitch, ASTM D4072-1998, ASTM international, 1998, West Conshohocken, PA, USA

52. American Society for Testing and Materials, Test method for toluene insoluble (TI) content of tar and pitch, ANSI/ASTM D 4072-1998 (R2004), (Reaffirmation of ANSI/ASTM D 4072-1998), ASTM international, 2004, West Conshohocken, PA, USA

53. International Organization for Standardization, Carbonaceous materials for the production of aluminum-pitch for electrodes
- determination of coking value, ISO-6998, 1997, Geneva, Switzerland

Publisher's Note Springer Nature remains neutral with regard to jurisdictional claims in published maps and institutional affiliations. 